\title{
STUDY OF GENETIC VARIATION IN DIFFERENT HATCHERY POPULATIONS OF COMMON CARP (CYPRINUS CARPIO) OF MYMENSINGH DISTRICT IN BANGLADESH USING MICROSATLLITE DNA MARKERS
}

\author{
M A S Jewel ${ }^{1 *}, M_{M}$ Rahman ${ }^{1}$ and M N Islam² \\ ${ }^{1}$ Department of Fisheries, Faculty of Agriculture, Rajshahi University, Rajshahi-6205 \\ ${ }^{2}$ Department of Biotechnology, Bangladesh Agricultural University, Mymensingh-2202
}

\begin{abstract}
Genetic variation of two strains (Scaled and Mirror) of six hatchery populations of common carp (Cyprinus carpio) was studied using three microsatellite loci (MFW13, MFW17 and MFW28). The loci were amplified by Polymerase Chain Reaction (PCR). The PCR products were electrophoresed on $6 \%$ polyacrylamide gel and the alleles were visualized by silver nitrate staining. All the three loci were found polymorphic. The average number of alleles was the highest in the population *SC-SMK (5.00) and lowest in ${ }^{* *}$ MC-SMK (4.00). Total number of null allele was more in mirror carp populations (6) than scaled carp populations (4). The average observed heterozygosity $\left(H_{0}\right)$ ranged from 0.54 to 0.67 . The average observed heterozygosity $\left(H_{0}\right)$ was lower than the average expected heterozygosity $\left(H_{e}\right)$ in case of all the populations. The population ${ }^{* *} \mathrm{SC}-\mathrm{BCH}$ had high level of genetic variation in comparison to other five populations because this population had negative $1-H_{0} / H_{e}$ values in case of two loci out of three analyzed. The rest five populations had negative $1-H_{0} / H_{e}$ values only in one locus. In 6 of a total of 18 tests, significant deviations from Hardy-Weinberg expectations (HWE) were detected. Pairwise Fst values were used to detect the genetic distance between the pairs of populations. The Fst value was highest (0.153) between the population MC-AFF and MC-SMK. Nei's genetic distance value was also highest (0.462) between these populations. The Fst value of 0.153 represents a high level of population differentiation. The lowest $F$ st value $(0.001)$ was found between SC-SMK and MC-SMK. This value was statistically insignificant.
\end{abstract}

*SC-SMK- scaled carp from Sagor Matsho Khamar

**MC - SMK- mirror carp from Sagor Matsho Khamar

***SC-BCH- scaled carp from Brahmaputra Char Fishery

Key words: Genetic variation, common carp, Microsatllite DNA markers

\section{Introduction}

Common carp is provably the oldest and most extensively cultured and domesticated species in the world. They have been farmed for about 4,000 years in China and for several hundred years in Europe (Wohlfarth 1984). The world annual total production of common carp in 2001 was estimated above 3 million metric tons, compared to the 2.3 million tons of Salmonids (FAO $2001 \mathrm{a}, \mathrm{b}$ ). There are numerous strains of common carp with three general groupings based on different scale patterns, viz, i) scaled carp, C. carpio var. communis

\footnotetext{
* To whom all correspondence should be addressed.
} 
ii) mirror carp, C. carpio var. specularis iii) leather carp, C. carpio var. nudus and iv) line carp, C. carpio var. line. Common carp varieties (eg. raees, landraces, strains, breeds and stocks) have been developed through a combination of forces including geographical isolation, adaptation, accumulation of mutations and natural as well as human selection pressure (Hulata 1995). Scale pattern in common carp is controlled by $\mathrm{S}$ and $\mathrm{N}$ genes which are produced through a type of dominant epistasis where $\mathrm{N}$ gene is the epistatic locus but it is a dominant lethal epistatic gene. Scale pattern in common carp is of great importance because mirror carps demand higher market price in Europe and sealed carp is more desired in Asia (Wohlfarth et al.).

Although Bangladesh is rich in endemic genetic resources (260 fresh water fish and 24 prawn species; 475 marine water fish and 36 shrimp species) (DOF 2003), introduction of different varieties of fish species has been occurring since 1960 (Rahman 1985). As many as 15 exotic culturable fishes (Ali 1998) have been deliberately introduced into Bangladesh waters with the objectives of increasing fish production and for insect and weed control. Among them, common carp is one of the most important fishes that is being extensively cultured throughout the country. Scaled common carp was first introduced in Bangladesh by the Department of Fisheries in 1960 from China and then second batch in 1995 from Vietnam (Rahman 1985, Hussain 1997). The mirror carp was first introduced in Bangladesh in 1979 from Nepal and then second and third batches from Hungary in 1982 and 1996 respectively.

In Bangladesh, common carp is bred repeatedly in the hatchery with limited number of parents in the hatchery to keep the production cost at minimum level. As a result genetic erosion may have occurred through inbreeding, genetic drift and bottleneck effect in the hatchery populations. The present study was conducted to asses the genetic variation among the different hatchery populations of scaled carp and mirror carp and to compare the genetic variability between different populations using microsatellite loci developed by Croojmans et al. (1997).

\section{Materials and Methods}

Three populations of scale common carp fingerlings and three populations of mirror carp fingerlings were collected from different hatcheries of Mymensingh district viz., as Sagor Matsho Khamar (SMK), Adorsho Matsho Khamar (AMK), Brahmaputra Char Fishery (BCH) and Anil Fish Farm (AFF). Samples of fin tissues were excised and preserved in $95 \%$ ethanol and stored at $-18^{\circ} \mathrm{C}$.

\section{Genomic DNA extraction}

For each sample approximately $30 \mathrm{mg}$ of fin tissues was cut into small pieces and genomic DNA was extracted by proteinase-K digestion, phenol: chloroform: isoamyl alcohl extraction and ethanol precipitation method as described by Alam et al. (1996) with some modifications. The confirmation of the presence of DNA in extracted solution was done by electrophoresis of samples in $1 \%$ agarose gel and observing the gel under UV light on UV-transilluminator. 


\section{Microsatellite marker amplification}

Three poly (CA) type microsatellite markers such as MFW13, MFW17 and MFW28, developed by Croojmans et al. (1997) were used. The annealing temperature of the primer pairs were adjusted to $55^{\circ} \mathrm{C}$ for MFW13, MFW17, and MFW28. PCR was performed in a $10 \mu$ reaction volume containing 25-50 ng templates DNA, DNAPs, 1 unit of taq DNA polymerase and $1 \mu \mathrm{l} 10 \times$ reaction buffers. The temperature profile consisted of 3 minutes initial denaturation at $94^{\circ} \mathrm{C}$. Then 30 seconds at $94^{\circ} \mathrm{C}, 30$ seconds at $55^{\circ} \mathrm{C}$ and 1 minute at $72^{\circ} \mathrm{C}$. Finally an additional 5 minutes at $72^{\circ} \mathrm{C}$ for elongation following the last cycle.

\section{Gel electrophoresis and staining}

PCR products were separated on $6 \%$ denatured polyacrylamide gel containing 19:1 acrylamide: bisacrylamide and $7 \mathrm{M}$ urea. The gel chamber $38 \times 30 \mathrm{~cm}$ Sequi-Gen GT sequencing gel electrophoresis system, $B I O F A D$ was used to conduct electrophoresis. After completion of electrophoresis, the gel was stained with silver nitrate following Promega (Madison, WI) silver staining protocol.

\section{Analysis of microsatallite data}

The bands representing particular alleles at the microsatellite loci were scored manually by two persons independently. The bands were designated as $a, b, c, d$, e and f from the top to the bottom of the gel. The software DNA FRAG version 3.03 (Schaffer and Sederoff 1981) was used to estimate allelic length. Allelic variation among the different populations and fit to Hardy-Weinberg proportions were estimated by the software POPGENE (version 1.31) (Yeh et al. 1999) with 1000 simulated samples. The software G-stat (Siegismund 1995) was used to estimate allelic frequencies and homogeneity test among the different populations. The software FSTAT version 2.9.3 (Goudet 2001) was used to calculate F-statistics (Fst) between populations. The software GDA (Lewis and Zaykin 2001) was used for estimating genetic distance.

\section{Results}

\section{Genetic variation in different populations}

The locus MFWI3 had the highest number of alleles (6) followed by MFW17 (5) and MFW28 (4). The average number of alleles was highest in the population SC-SMK (5.00) followed by MC- AMK (4.67). The populations SC-AMK, SC-BCH and MC-AFF were found to have average 4.33 alleles. The population MCSMK had the least number of average alleles (4.00). The observed average heterozygocity $\left(H_{0}\right)$ was highest in the population SC-SMK (0.67) followed by SC-BCH and MC-BCH (0.65); SC-AMK (0.63); MC-SMK (0.55) in a descending order. $H_{0}$ was lowest in MC- AFF (0.54) (Table 1.)

The allelic frequencies of all the loci in all the populations are shown in the table 2. The Sizes of alleles ranged from 155 to $198 \mathrm{bp}$ for the locus MFW13, 234 to 277bp for the locus MFW17 and 290 to $307 \mathrm{bp}$ for the locus MFW 28. Mirror carp populations had more null alleles than scaled carp populations. The population SC-SMK was found to have all the alleles at all the loci. 
Table 1. Allelic variations at three microsatellite loci in different populations of two strains of $C$. carpio $(N=$ No. of alleles, $H_{0}=$ heterozygosity observed, $H_{\mathrm{e}}=$ heterozygosity expected).

\begin{tabular}{|c|c|c|c|c|c|c|}
\hline \multirow[b]{3}{*}{ Parameters } & \multicolumn{6}{|c|}{ Populations } \\
\hline & \multicolumn{3}{|c|}{ Scaled carp } & \multicolumn{3}{|c|}{ Mirror carp } \\
\hline & 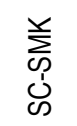 & 旁 & $\begin{array}{l}\text { I } \\
\text { ' } \\
\text { U্' }\end{array}$ & $\begin{array}{l}\stackrel{y}{k} \\
\text { J } \\
\sum\end{array}$ & $\begin{array}{l}\text { 晏 } \\
\text { 它 }\end{array}$ & $\begin{array}{l}\sum_{\text {Co }} \\
\text { U. }\end{array}$ \\
\hline \multicolumn{7}{|l|}{ MFW13 } \\
\hline N & 6 & 5 & 5 & 5 & 5 & 5 \\
\hline$H_{0}$ & 0.73 & 0.77 & 0.70 & 0.78 & 0.62 & 0.73 \\
\hline$H_{\mathrm{e}}$ & 0.77 & 0.72 & 0.75 & 0.70 & 0.76 & 0.75 \\
\hline $1-H_{0} / H_{\mathrm{e}}$ & 0.03 & -0.09 & -0.04 & -0.14 & 0.17 & -0.02 \\
\hline \multicolumn{7}{|l|}{ MFW17 } \\
\hline$N$ & 5 & 5 & 5 & 5 & 5 & 4 \\
\hline$H_{0}$ & 0.85 & 0.70 & 0.74 & 0.60 & 0.65 & 0.64 \\
\hline $\mathrm{He}_{\mathrm{e}}$ & 0.78 & 0.79 & 0.74 & 0.75 & 0.57 & 0.72 \\
\hline $1-H_{0} / H_{\mathrm{e}}$ & -0.10 & 0.10 & -0.02 & 0.19 & -0.18 & 0.07 \\
\hline \multicolumn{7}{|l|}{ MFW28 } \\
\hline$N$ & 4 & 3 & 3 & 4 & 3 & 3 \\
\hline$H_{0}$ & 0.42 & 0.42 & 0.52 & 0.59 & 0.35 & 0.27 \\
\hline $\mathrm{He}_{\mathrm{e}}$ & 0.65 & 0.63 & 0.67 & 0.69 & 0.47 & 0.69 \\
\hline $1-H_{0} / H_{e}$ & 0.34 & 0.31 & 0.21 & 0.12 & 0.25 & 0.57 \\
\hline Average $H_{0}$ over loci & 0.67 & 0.63 & 0.65 & 0.65 & 0.54 & 0.55 \\
\hline Average $H_{\mathrm{e}}$ over loci & 0.73 & 0.71 & 0.72 & 0.71 & 0.60 & 0.72 \\
\hline Average number of alleles & 5.00 & 4.33 & 4.33 & 4.67 & 4.33 & 4.00 \\
\hline Polymorphism $\left(P_{95}\right)$ & 1.00 & 1.00 & 1.00 & 1.00 & 1.00 & 1.00 \\
\hline
\end{tabular}

\section{Deviation from Hardy-Weinberg proportion}

The test for fit to Hardy-Weinberg proportions revealed that, at locus MFW13 all the populations were found to have no deviation from Hardy-Weinberg expectations except the population MC-AFF and except the population MC-AMK at locus MFW17. But at locus MFW28 all the populations were found deviated from Hardy-Weinberg expectations except the populations SC-SMK and SC-BCH (Table 3).

\section{Inter-population genetic structure}

The Fst (population differentiation) value between the population MC-AFF and MC-SMK was the highest (0.153) while the Fst value between SC-SMK and MC-SMK was the lowest (0.001). The Nei's genetic distance value between MC- SMK and MC- AFF was also the highest (0.462) across all the studied loci (Table 4).

Pair-wise comparisons of six population samples of $C$. carpio using homogeneity tests are shown in Table 5. The population pairs SC-SMK/SC-AMK, SC-SMK/SC-BCH and SC-SMK/MC-SMK were homogenous at all the loci. But the population pairs SC-SMK/MC-AFF, SC-AMK/MC-AFF, MC-AMK/MC-AFF and MC-AFF/MCSMK were not homogeneous at any locus. 
Table 2. Frequency of alleles at three microsatellite loci in different populations of two strains of $C$. carpio.

\begin{tabular}{|c|c|c|c|c|c|c|}
\hline \multirow{3}{*}{$\begin{array}{l}\text { Allele size } \\
\text { (bp) }\end{array}$} & \multicolumn{6}{|c|}{ Populations } \\
\hline & \multicolumn{3}{|c|}{ Scaled carp } & \multicolumn{3}{|c|}{ Mirror carp } \\
\hline & SC-SMK & SC-AMK & $\mathrm{SC}-\mathrm{BCH}$ & MC-AMK & MC-AFF & MC-SMK \\
\hline \multicolumn{7}{|l|}{ MFW13 } \\
\hline 198 & 0.19 & 0.23 & 0.26 & 0.33 & 0.10 & 0.41 \\
\hline 191 & 0.17 & 0.13 & 0.06 & 0.11 & 0.12 & 0.09 \\
\hline 184 & 0.33 & 0.44 & 0.37 & 0.43 & 0.40 & 0.18 \\
\hline 178 & 0.02 & 0 & 0 & 0.04 & 0 & 0 \\
\hline 167 & 0.02 & 0.02 & 0.09 & 0 & 0.21 & 0.05 \\
\hline 155 & 0.27 & 0.17 & 0.22 & 0.09 & 0.17 & 0.27 \\
\hline \multicolumn{7}{|l|}{ MFW17 } \\
\hline 277 & 0.19 & 0.17 & 0.31 & 0.37 & 0.60 & 0 \\
\hline 263 & 0.19 & 0.10 & 0.17 & 0.11 & 0.06 & 0.27 \\
\hline 253 & 0.35 & 0.33 & 0.37 & 0.24 & 0.29 & 0.45 \\
\hline 243 & 0.17 & 0.21 & 0.06 & 0.24 & 0.04 & 0.14 \\
\hline 234 & 0.10 & 0.19 & 0.09 & 0.04 & 0.02 & 0.14 \\
\hline \multicolumn{7}{|l|}{ MFW28 } \\
\hline 307 & 0.04 & 0 & 0 & 0.04 & 0 & 0 \\
\hline 297 & 0.44 & 0.27 & 0.26 & 0.24 & 0.67 & 0.32 \\
\hline 294 & 0.38 & 0.52 & 0.43 & 0.41 & 0.29 & 0.45 \\
\hline 290 & 0.13 & 0.21 & 0.31 & 0.31 & 0.04 & 0.23 \\
\hline $\begin{array}{l}\text { Total nos. of } \\
\text { null alleles } \\
\text { across the } \\
\text { loci }\end{array}$ & 0 & 2 & 2 & 1 & 2 & 3 \\
\hline
\end{tabular}

Table 3. Deviation from Hardy-Weinberg expectations in different populations of two strains of $C$. carpio $L$. $X^{2}$ values followed by degrees of freedom in parenthesis.

\begin{tabular}{|c|c|c|c|c|c|c|}
\hline \multirow[t]{3}{*}{ Loci } & \multicolumn{6}{|c|}{ Populations } \\
\hline & \multicolumn{3}{|c|}{ Scaled carp } & \multicolumn{3}{|c|}{ Mirror carp } \\
\hline & SC-SMK & SC-AMK & SC-BCH & MC-AMK & MC-AFF & MC-SMK \\
\hline \multicolumn{7}{|l|}{ MFW13 } \\
\hline & $\begin{array}{c}\text { 14.41 NS } \\
(15)\end{array}$ & $\begin{array}{c}6.86 \mathrm{NS} \\
(10)\end{array}$ & $\begin{array}{c}\text { 7.85 NS } \\
(10)\end{array}$ & $\begin{array}{c}2.93 \mathrm{NS} \\
(10)\end{array}$ & $\begin{array}{c}29.21^{* \star} \\
(10)\end{array}$ & $\begin{array}{c}8.29 \text { NS } \\
(10)\end{array}$ \\
\hline \multicolumn{7}{|l|}{ MFW17 } \\
\hline & $\begin{array}{c}9.10 \mathrm{NS} \\
(10)\end{array}$ & $\begin{array}{c}15.43 \mathrm{NS} \\
(10)\end{array}$ & $\begin{array}{c}5.09 \mathrm{NS} \\
(10)\end{array}$ & $\begin{array}{c}23.16^{*} \\
(10)\end{array}$ & $\begin{array}{c}9.95 \mathrm{NS} \\
(10)\end{array}$ & $\begin{array}{c}5.80 \mathrm{NS} \\
(6)\end{array}$ \\
\hline \multicolumn{7}{|l|}{ MFW28 } \\
\hline & $\begin{array}{c}7.70 \text { NS } \\
(6)\end{array}$ & $\begin{array}{l}9.76^{*} \\
(3)\end{array}$ & $\begin{array}{c}3.68 \mathrm{NS} \\
(3)\end{array}$ & $\begin{array}{c}12.59^{*} \\
(6)\end{array}$ & $\begin{array}{c}51.73^{\star \star \star} \\
(3)\end{array}$ & $\begin{array}{c}10.67^{*} \\
(3)\end{array}$ \\
\hline
\end{tabular}

Statistically significant values are marked with asterisks, ${ }^{*} P<0.05,{ }^{* *} P<0.01$, and ${ }^{* *} P=0000$, NS= Not Significant 
Table 4. Multilocus FST (above diagonal) and Nei's (1972) genetic distance (below diagonal) values between pairs of different populations of two strains of $C$. carpio $L$. across all loci.

\begin{tabular}{|l|l|l|l|l|l|l|l|}
\hline \multirow{4}{*}{} & & \multicolumn{3}{|c|}{ Scaled carp } & \multicolumn{3}{c|}{ Mirror carp } \\
\cline { 2 - 8 } & & SC-SMK & SC-AMK & SC-BCH & MC-AMK & MC-AFF & MC-SMK \\
\cline { 2 - 8 } $\begin{array}{l}\text { Scaled } \\
\text { Carp }\end{array}$ & SC-SMK & --- & 0.002 & 0.009 & 0.024 & $0.062^{*}$ & 0.001 \\
\cline { 2 - 8 } & SC-AMK & 0.059 & --- & 0.003 & 0.007 & $0.105^{*}$ & 0.011 \\
\cline { 2 - 8 } & SC-BCH & 0.076 & 0.058 & --- & 0.003 & $0.078^{*}$ & 0.011 \\
\hline $\begin{array}{l}\text { Mirror } \\
\text { carp }\end{array}$ & MC-AMK & 0.119 & 0.066 & 0.058 & -- & $0.093^{*}$ & $0.043^{*}$ \\
\cline { 2 - 8 } & MC-AFF & 0.163 & 0.280 & 0.204 & 0.244 & --- & $0.153^{*}$ \\
\cline { 2 - 8 } & MC-SMK & 0.093 & 0.116 & 0.115 & 0.206 & 0.462 & --- \\
\hline
\end{tabular}

Statistically significant values are marked with asterisks, ${ }^{*} P<0.05$

Table 5. Homogeneity between samples of $C$. carpio $L . X^{2}$ values followed by degrees of freedom in parentheses.

\begin{tabular}{|c|c|c|c|}
\hline Populations & \multicolumn{3}{|c|}{$x^{2}$-values } \\
\hline & MFW13 & MFW17 & MFW28 \\
\hline SC-SMK / SC-AMK & 2.66 (3) NS & 3.68 (4) NS & 3.46 (2) NS \\
\hline SC-SMK/ SC-BCH & 5.5 (4) NS & 5.10 (4) NS & $4.88(2) \mathrm{NS}$ \\
\hline SC-SMK / MC-AMK & $8.10(3)^{*}$ & 7.24 (4) NS & $6.52(2)^{*}$ \\
\hline SC-SMK/ MC-AFF & $10.68(3)^{*}$ & $23.26(4)^{\star * *}$ & $8.04(2)^{*}$ \\
\hline SC-SMK / MC-SMK & $4.35(3) \mathrm{NS}$ & 8.32 (4) NS & $1.03(2) \mathrm{NS}$ \\
\hline SC-AMK / SC-BCH & $5.31(4) \mathrm{NS}$ & $10.43(4)^{*}$ & $1.58(2) \mathrm{NS}$ \\
\hline SC-AMK / MC-AMK & 2.33(3) NS & $10.86(4)^{*}$ & $1.80(2) \mathrm{NS}$ \\
\hline SC-AMK / MC-AFF & $12.89(4)^{*}$ & $28.84(4)^{\star \star \star \star *}$ & $19.63(2)^{\star \star \star \star}$ \\
\hline SC-AMK / MC-SMK & $5.65(3) \mathrm{NS}$ & $10.72(4)^{*}$ & $0.28(2) \mathrm{NS}$ \\
\hline SC-BCH / MC-AMK & $6.03(4) \mathrm{NS}$ & $10.41(4)^{*}$ & $0.06(2) \mathrm{NS}$ \\
\hline SC-BCH / MC-AFF & 8.18 (4) NS & $11.07(4)^{*}$ & $24.51(2)^{\star \star \star \star \star}$ \\
\hline SC-BCH / MC-SMK & 3.23 (3) NS & $13.95(3)^{* \star}$ & $0.65(2) \mathrm{NS}$ \\
\hline MC-AMK/ MC-AFF & $15.87(4)^{\star *}$ & $12.87(3)^{\star \star}$ & $27.67(2)^{\star \star \star \star *}$ \\
\hline MC-AMK / MC-SMK & 6.38 (3) NS & $21.01(3)^{\star * *}$ & $0.60(2) \mathrm{NS}$ \\
\hline MC-AFF / MC-SMK & $13.76(4)^{\star \star}$ & $33.50(3)^{\star \star \star \star \star *}$ & $10.19(2)^{\star *}$ \\
\hline
\end{tabular}

\section{Discussion}

The average observed heterozygosities $\left(H_{0}\right)$ of all the six populations were varied form 0.54 to 0.67 . The average expected heterozygosities $\left(\mathrm{H}_{\mathrm{e}}\right)$ were varied from 0.60 to 0.73 . The $\mathrm{Ho}_{s}$ were lower than the $\mathrm{He}_{s}$ in case of all the populations. This means that all the populations have some losses of heterozygosity. The result of Ho was not consistent with the result of average number of alleles. The population SC-SMK had the highest $H o(0.67)$ and average number of alleles (5.00). Thus genetic variability was higher in this population. The genetic variabilities of the population SC-AMK and SC-BCH were more or less similar in terms of $\mathrm{Ho}$ and 
average number of alleles. The population MC-SMK had the lowest average number of alleles (4.00). Loss of allelic variation has been reported for Polish hatchery populations of trout (Was and Wenne 2002). Similarly, Sekino et al. (2002) found that the number of microsatellite alleles was markedly reduced in the hatchery strains compared with the wild populations in Japanese flounder. Microsatellites are generally considered to be selectively neutral and it can be said that the reduction of microsatellite allelic diversity in the population MC-SMK could be related to a possible population bottleneck associated with breeding practice.

There were no deviations from Hardy-Weinberg expectations found in the populations SC-SMK and SC$\mathrm{BCH}$. That means, these two populations had lower level of loss of heterozygosity. Only one population of scaled carp and all three populations of mirror carp had deviation from Hardy-Weinberg expectation at some loci. Repeatedly, mirror carp populations were found to have more null allele (6) than scaled carp populations (4). That means the mirror carp strain had relatively higher level of loss of allelic variations and loss of heterozygosity than scaled carp strain.

The deviation of mirror carp strain from equilibrium might be due to loss of heterozygosity in hatchery populations as a result of bottleneck, inbreeding and genetic drift. Higher level of loss of allelic variation in mirror carp than scaled carp may be due to the fact that scaled carp was introduced into Bangladesh in two batches while mirror carp in three batches and bred repeatedly in the hatcheries with small effective number of broods ( $\mathrm{Ne})$. As a result genetic erosion might have happened in most of the hatchery populations through inbreeding and genetic drift. The losses of heterozygosity may be increased with the increasing effect of inbreeding. Alam and Islam (2005) also found that the population of Catla catla was deviated from HardyWeinberg equilibrium at a number of loci.

Pair wise Fst values were used to detect the genetic distance between the pairs of populations. The Fst value was highest (0.153) between the population MC-AFF and MC-SMK. The Fst value of 0.153 represents a high level of population differentiation. Nei's genetic distance value was also highest $(0.462)$ between these populations. The underlying causes of the highest genetic distance between two mirror carp population instead scaled carp and mirror carp was unknown. On the other hand the lowest $F s t$ value $(0.001)$ was found between SC-SMK and MC-SMK. This value was statistically insignificant. That means, these two populations are genetically very similar to each other. The cause may be, these two populations were collected from the same fishery (SMK) and provably they were produced by cross-breeding between scaled carp and mirror carp. Now a days indiscriminate hybridization is a common practice in most of the fish hatcheries in Bangladesh. Non-significant population differentiation was also observed in several comparisons within regions, in particular between German pond carp or between Uzbek wild carp (Kohlmann et al. 2003). In contrast, highly significant population differentiation was found between Uzbek wild and Uzbek domesticated, Uzbek and German, Uzbek and East Asian, and German and East Asian common carp populations (Murakaeva et al. 2003).

\section{References}

Alam M S and Islam M S (2005) Population genetics of Catla catla (Hamilton) revealed by microsatellite DNA markers. Aquaculture 246: 151-160.

Alam M S, Popplewell A and Maclean N (1996) Germline transmission and expression of a lacZ containing transgene in tilapia (Oreochromis niloticus). Transgenic Research 5: 87-95.

Ali M L (1998) Fisheries resources development and management technique. Fish Week' 98 Compendium. Department of Fisheries, Ministry of Fisheries and Livestock, Government of the Peoples Republic of Bangladesh, Dhaka, pp. 1-10.

Crooijmans R P M, Bierbooms V A F, Komen J, van der Poel J J and Groenen M A M (1997) Microsatellite markers in common carp (Cyprinus carpio L.). Animal Genetics 28: 129-134. 
DOF (2003) Fish-Fortnight Compendium, Department of Fisheries, Ministry of Fisheries and Livestock, Government of the Peoples' Republic of Bangladesh pp. 110-114.

FAO (2001a) Fishery statistics: Capture production. Vol. 92/1, FAO, Rome, Italy.

FAO (2001b) Fishery statistics: Aquaculture production. Vol. 92/2, FAO, Rome, Italy.

Goudet J (2001) FSTAT, a program to estimate and test gene diversities and fixation indices (version 2.9.3). Available from http://www.unil.ch/izea/softwares/ Fstat.html. Updated from Goudet (1995).

Hulata G (1995) A review of genetic improvement of the common carp (Cyprinus carpio L.) and other cyprinids by crossbreeding, hybridization and selection. Aquaculture 129: 143-155.

Hussain M G (1997) Current status of carp genetic research and breeding practices in Bangladesh. In: M V Gupta, M M Dey, R. Dunham and G Bimbao (eds.), Proceedings of the Collabarative Research and Training on Genetic Improvement of carp species in Asia, 26-29 July, 1997. Central Institute of Freshwater Aquaculture, Bhubaneshwar, India. ICLARM Work Documents 1 (Unpublished), $12 p$.

Kohlmann K, Gross R, Murakaeva A and Kersten P (2003) Genetic variability and structure of common carp (Cyprinus carpio) populations throughout the distribution range inferred from allozyme, microsatellite and mitochondrial DNA markers. Aquatic Living Resources 16: 421-431.

Lewis P O and Zaykin D (2001) Genetic Data Analysis: Computer program for the analysis of allelic data. Version 1.0 (d 16c). Free program distributed by the authors over the internet from http://lewis.eeb.uconn.edu/lewishome/software. html

Murakaeva A, Kohlmann K, Kersten P, Kamilov B and Khabibullin D (2003) Genetic characterization of wild and domesticated common carp (Cyprinus carpio L.) population from Uzbekistan. Aquaculture 218: 1-4, 153-166; 24.

Rahman A K M (1985) Study on the exotic fishes in Bangladesh. Paper presented at a seminar on the Culture Need of Exotic Species in Bangladesh organized by the Zoological Society of Bangladesh, Dhaka on 15 October, 1984, p. 13.

Schaffer H E and Sederoff R R (1981) Least squares fit of DNA fragment length to gel mobility. Algorithm of Analytical Biochemistry 115: 113-122.

Sekino M, Hara M and Taniguchi N (2002) Genetic diversity within and between hatchery strains of Japanese flounder Paralichthys olivaceus assessed by means of microsatellite and mitochondrial DNA sequencing analysis. Aquaculture 213: $101-122$.

Siegismund H R (1995) G-STAT, Version 3.1. Genetical statistical programs for the analysis of population data. Botanical Institute, University of Copenhagen, Denmark.

Was A and Wenne R (2002) Genetic differentiation in hatchery and wild sea trout (Salmo trutta) in the Southern Baltic at microsatellite loci. Aquaculture 204: 493-506.

Wohlfarth G W (1984) Common carp. In: L. Mason (ed.), Evolution of domesticated animals. Longman, Harlow, UK, pp. 375-380.

Wohlfarth G W, Lahman M and Moav R (1963) Genetic improvement of carp. IV. Leather and Line carp in fish ponds of Israel. Bamidgeh 15: 3-8.

Yeh F C, Yang R C and Boyle T (1999) POPGENE VERSION 1.31: Microsoft Window-based free Software for Population Genetic Analysis. ftp://ftp.microsoft.com/Softlib/HPGL.EXE. 